\title{
CLINICAL AND ELECTROPHYSIOLOGICAL STUDY OF LEPROUS NEURITIS
}

\author{
G. Surya Narayana ${ }^{1}$, C. Subhashini ${ }^{2}$, B. Balachandrudu ${ }^{3}$ S. Jahnavi ${ }^{4}$, Ch. Naveen Kumar 5 , Suneetha Patro ${ }^{6}$, Divya ${ }^{7}$, P. Guru Prasad ${ }^{8}$
}

${ }^{1}$ Assistant Professor, Department of DVL, Andhra Medical College, Visakhapatnam.

${ }^{2}$ Assistant Professor, Department of DVL, Andhra Medical College, Visakhapatnam.

3 Professor \& HOD, Department of DVL, Andhra Medical College, Visakhapatnam.

4Junior Resident, Department of DVL, Andhra Medical College, Visakhapatnam.

$5 J u n i o r$ Resident, Department of DVL, Andhra Medical College, Visakhapatnam.

6Junior Resident, Department of DVL, Andhra Medical College, Visakhapatnam.

${ }_{7}^{7}$ Senior Resident, Department of DVL, Andhra Medical College, Visakhapatnam.

${ }^{8}$ Associate Professor, Department of DVL, Andhra Medical College, Visakhapatnam.

\section{ABSTRACT}

\section{BACKGROUND}

Leprosy involves peripheral nerves sooner or later in the course of disease leading to gross deformities and disabilities. However, if the preclinical damage is detected early in the course of disease, it can be prevented to a large extent.

\section{MATERIALS AND METHODS}

The present study comprises of 50 new cases of various types of leprosy who attended Department of Dermatology, King George Hospital, Visakhapatnam during the period from September 2004 to August 2005. All these cases were clinically examined along with relevant investigation including slit-skin smear. These cases were subjected to nerve conduction studies in the Department of Neurology to assess the motor and sensory involvement.

\section{RESULTS}

There is a significant reduction in NCV and amplitude and reduced latency in MB cases when compared to PB. In 3 cases of multibacillary leprosy, motor component of ulnar nerve could not be elicited with maximum stimulation.

\section{CONCLUSION}

All patients of leprosy should have nerve function assessment in every visit during first year of treatment. Regular nerve function assessment is essential to detect silent neuropathy to prevent permanent disabilities and deformities. Hence, nerve conduction studies along with clinical assessment may definitely help to assess the damaged nerves in leprosy.

\section{KEYWORDS}

Electrophysiology, Leprosy, Nerve Conduction Study.

HOW TO CITE THIS ARTICLE: Narayana GS, C. Subhashini C, Balachandrudu B, et al. Clinical and electrophysiological study of leprous neuritis. J. Evolution Med. Dent. Sci. 2017;6(21):1736-1739, DOI: 10.14260/Jemds/2017/381

\section{BACKGROUND}

Leprosy is one of the principal causes of non-traumatic neuropathy and clinically manifests as hypopigmented anaesthetic patches of skin with involvement of peripheral nerves. Functional derangement of nerves can be shown by nerve conduction studies before appearance of clinical signs and symptoms of the disease. Functional defect in conduction velocity in nerves always precedes clinical manifestation. Role of electrophysiological evaluation of nerve function in the diagnosis and assessment of various neuropathies has been studied.

\section{Aims and Objectives}

1. To detect nerve function impairment at early stage.

2. To correlate clinical involvement of nerve and the corresponding electrophysiological changes.

Financial or Other, Competing Interest: None.

Submission 15-12-2016, Peer Review 27-02-2017,

Acceptance 04-03-2017, Published 13-03-2017.

Corresponding Author:

Dr. G. Surya Narayana,

Assistant Professor

Department of DVL, KGH,

Maharanipet, Visakhapatnam-523002.

E-mail: gppatnala@yahoo.co.in

DOI: $10.14260 /$ jemds $/ 2017 / 381$

\section{(c) $(1) \subseteq$}

3. To know specific electrophysiological changes of peripheral nerves in different types of leprosy.

4. To assess nerve function impairment along with other standard tests.

\section{MATERIALS AND METHODS}

The present study comprises of 50 new cases of various types of Leprosy who attended Department of Dermatology, King George Hospital, Visakhapatnam during the period from September 2004 to August 2005. All these cases were clinically examined along with relevant investigation including slit-skin smear. These cases were subjected to nerve conduction studies in the Department of Neurology to assess the motor and sensory involvement.

\section{Inclusion Criteria}

New cases of all types of leprosy.

Age $>=10$ years.

\section{Exclusion Criteria}

Patients in reaction.

Patients already on steroid therapy.

Other systemic illnesses.

Clinical history was taken and classified patients according to Ridley-Jopling classification. Routine haematological, biochemical and standard tests for nerve function impairment were done. Slit-skin smear was done in 
all cases (3 smears- 1 from earlobe, 2 from patches). Nerve conduction studies were done by Medicaid two channel digital EMG NCV-NP2300W, Dept. of Neurology. Nerves tested were Median, Ulnar, Radial, Peroneal, Tibial, Sural nerve.

\section{Procedure of NCS}

After preparation of the skin, square wave stimuli of $0-500$ volts amplitude and $0.1 \mathrm{msec}$ duration were applied to the skin along the distal end of nerves at frequency of 1 per second using disc electrodes and ring electrodes.

\begin{tabular}{|c|c|c|}
\hline Nerve & $\begin{array}{c}\text { Stimulating } \\
\text { Electrode }\end{array}$ & $\begin{array}{c}\text { Recording } \\
\text { Electrode }\end{array}$ \\
\hline RCI & $\begin{array}{c}2 \text { cm proximal to } \\
\text { metacarpal head of } \\
\text { index finger. }\end{array}$ & $\begin{array}{c}12 \mathrm{~cm} \text { proximal to } \\
\text { stimulating electrode } \\
\text { along the radial nerve }\end{array}$ \\
\hline Sural & $\begin{array}{c}2 \mathrm{~cm} \text { below } \\
\text { lateral malleolus }\end{array}$ & $\begin{array}{c}12 \mathrm{~cm} \text { proximal to } \\
\text { stimulating electrode } \\
\text { along the nerve in } \\
\text { mid-calf region. }\end{array}$ \\
\hline Median & Wrist & Cubital fossa \\
\hline Ulnar & $\begin{array}{c}\text { Dorsa of palm } \\
\text { ulnar border }\end{array}$ & $\begin{array}{c}2 \text { cm below or } 2 \mathrm{~cm} \\
\text { above medial epicondyle }\end{array}$ \\
\hline \multicolumn{2}{|c|}{ Electrode Position for Nerve Conduction Study } \\
\hline \multicolumn{2}{|c}{}
\end{tabular}

\section{For Motor Nerve Conduction}

Active electrode is placed over the motor point which is usually at the midpoint between the origin and insertion of the muscle. The reference electrode is placed on the tendon. Surface stimulation of nerves with intensity of 5-40 m amperes current done. The measurement of MNC includes latency, duration, amplitude and compound action potential are recorded.

\section{For Sensory Nerve Conduction Studies}

Both active and reference electrodes were placed on the nerve, electrode minimum distance is $4 \mathrm{~cm}$, the surface electrodes were placed with the help of electrode paste which provides interface between the patient and the equipment. After surface stimulation of the nerves, SNAP amplitude is measured. Velocity is measured by stimulating at a single site and the remaining measurements were similar to motor nerve conduction studies.

\section{RESULTS}

Study period September 2004 to August 2005.

- Total number of cases - 50

- B. T. Hansens - 30

- B. B. - 03

- B. L. -07

- L. L. 01

- P.N. - 09

\begin{tabular}{|c|c|c|}
\hline Age & Male & Female \\
\hline $10-20$ & 12 & 03 \\
\hline $21-30$ & 14 & 07 \\
\hline $31-40$ & 04 & 02 \\
\hline $41-50$ & 02 & 01 \\
\hline $51-60$ & 02 & 02 \\
\hline $61-65$ & 01 & 15 \\
\hline \multicolumn{2}{|c|}{ Age and Sex Distribution of the Cases } \\
\hline
\end{tabular}

Duration of the Disease

1 month to 4 years Neurological Study results.

\begin{tabular}{|c|c|c|c|c|c|c|}
\hline $\begin{array}{l}\text { Neurological } \\
\text { Manifestations }\end{array}$ & LL & BL & BT & TT & PN & Total \\
\hline $\begin{array}{l}\text { Cranial nerves affected } \\
\text { Trigeminal nerve }\end{array}$ & 1 & 3 & 2 & & & 6 \\
\hline Facial nerve & & & 3 & & & 3 \\
\hline \multicolumn{7}{|l|}{ Muscular system } \\
\hline Disability claw hands & & 2 & 2 & & 1 & 5 \\
\hline Flexion deformity of toes & & 1 & & & 1 & 2 \\
\hline \multicolumn{7}{|l|}{ Muscles wasting } \\
\hline Upper limbs & & 2 & 2 & & 1 & 5 \\
\hline Lower limbs & & 1 & 1 & & 3 & 5 \\
\hline $\begin{array}{c}\text { Sensory system } \\
\text { Superficial sensation } \\
\text { Mononeuropathy } \\
\text { Ulnar side }\end{array}$ & & & 11 & & 4 & 15 \\
\hline Radial side & & 2 & 2 & & 1 & 5 \\
\hline $\begin{array}{l}\text { Glove and stock } \\
\text { anaesthesia }\end{array}$ & 1 & & & & & \\
\hline Maculo-anaesthetic & 1 & 7 & 30 & & & 38 \\
\hline $\begin{array}{l}\text { Trophic and vasomotor } \\
\text { changes anhydrosis }\end{array}$ & & 4 & 12 & & 4 & 20 \\
\hline \multicolumn{7}{|c|}{$\begin{array}{l}\text { Neurological Manifestations in } \\
\text { Different types of Leprosy Patient }\end{array}$} \\
\hline
\end{tabular}

\section{Cranial Nerves}

The trigeminal nerve was the most common cranial nerve being involved in 6 cases out of 50 cases. The predominant manifestation of trigeminal nerve affection were mainly sensory manifestations in the form of hypoesthesia of face in 3 patients, anaesthesia of face in 3 patients, and loss of corneal reflexes in 6 patients. Other cranial nerve involved was facial nerve in 3 cases. One case with facial nerve involvement was manifested by lagophthalmos, there was severe inflammatory swelling of the whole right side of face and watering from the right eye.

\section{Muscular System}

The commonest disabilities in muscles were manifested by complete claw hand in 2 cases, partial claw in 3 cases and foot drop in 3 cases.

Wasting of the hands and forearm in 5 cases, wasting towards ulnar side flexors of the wrist, finger and thumb extension in 3 cases, unilateral wasting in thenar in 5 cases, bilateral distal wasting in 2 cases. In lower limbs, 3 foot drops cases, wasting in 3 cases, wasting of distal leg muscles towards peroneal side 3 cases, wasting of foot muscles.

\section{Sensory System}

Superficial sensation was most affected, diminished in almost all cases as shown.

Trophic and vasomotor changes: Anhydrosis in 21 cases, thickened ulnar nerve found in 31 cases unilateral, 5 cases bilateral ulnar thickening, thickened and great auricular nerve in 6 cases, thickened radial cutaneous nerve in 4 cases, thickened medial cutaneous nerve of forearm in 1 case, thickened cutaneous nerve of upper arm on right side, thickened common peroneal nerve in 17 cases. Thickened 
posterior tibial nerve in 8 cases, thickened sural nerve in 3

cases, thickened median nerve in 6 cases.

Nerve Conduction Results- Normal values for Representative Nerve Conduction Values at various sites of Stimulation (Mean values +2 SD for adults 16 to 65 years of Age).

\begin{tabular}{|c|c|c|c|c|c|c|c|c|c|c|c|c|c|}
\hline \multirow{2}{*}{ Nerve } & \multirow{2}{*}{$\begin{array}{c}\text { Distal } \\
\text { Stimulation } \\
\text { Site }\end{array}$} & \multirow{2}{*}{$\begin{array}{c}\text { Other } \\
\text { Stimulation } \\
\text { Sites }\end{array}$} & \multirow{2}{*}{$\begin{array}{l}\text { Recording } \\
\text { Site }\end{array}$} & \multicolumn{3}{|c|}{ Onset Latency (ms) } & \multicolumn{2}{|c|}{ AMP (mV) } & \multicolumn{2}{|c|}{$\mathrm{CV}(\mathrm{m} / \mathrm{s})$} & \multirow{2}{*}{$\begin{array}{c}\text { Distance } \\
\text { (cm) }\end{array}$} & \multicolumn{2}{|c|}{ f-latency } \\
\hline & & & & ULN & $\begin{array}{c}125 \\
\%\end{array}$ & $\begin{array}{c}150 \\
\%\end{array}$ & LLN & $\begin{array}{l}80 \\
\%\end{array}$ & LLN & $\begin{array}{l}80 \\
\%\end{array}$ & & ULN & $\begin{array}{c}125 \\
\%\end{array}$ \\
\hline Medial & Wrist & Elb & APB & $<4.2$ & 502 & 6.3 & $>4.4$ & 3.5 & $>49$ & 39 & $6-8$ & $<31$ & 39 \\
\hline Ulnar & Wrist & $\mathrm{BG}, \mathrm{AG}$ & ADM & $<3.4$ & 4.2 & 5.1 & $>6.0$ & 4.8 & $>49$ & 39 & $5.5-7.5$ & $<32$ & 40 \\
\hline Radial & Forearm & Elbow, SG & EIP & $<5.2$ & 6.5 & 7.8 & $>4.0$ & 3.2 & $>50$ & 40 & 10 & NA & \\
\hline Peroneal & Ankle & $\mathrm{BFH}, \mathrm{AFH}$ & EDB & $<5.8$ & 7.3 & 8.7 & $>2.0$ & 1.6 & $>42$ & 34 & $6-11$ & $<58$ & 72 \\
\hline Peroneal & BFH & AFH & TA & $<3.0$ & 3.8 & 4.5 & $>5.0$ & 4 & $>42$ & 34 & 10 & NA & \\
\hline Tibial & Ankle & $\mathrm{PF}$ & $\mathrm{AH}$ & $<6.5$ & 8.1 & 9.8 & $>3.0$ & 2.4 & $>41$ & 33 & 6.8 & $<59$ & 74 \\
\hline
\end{tabular}

\begin{tabular}{|c|c|c|c|c|c|c|c|}
\hline Nerve & Distal Stimulation Site & Recording Site & Onset latency (ms) & $\begin{array}{c}\text { Peak } \\
\text { Latency (ms) }\end{array}$ & $\begin{array}{c}\text { AMP } \\
(\mathbf{m V})\end{array}$ & $\begin{array}{c}\text { CV } \\
(\mathbf{m} / \mathbf{s})\end{array}$ & $\begin{array}{c}\text { Distance } \\
(\mathbf{c m})\end{array}$ \\
\hline Median & Wrist & Digit 2 & $<2.5$ & $<3.5$ & $>20$ & $>52$ & 13 \\
\hline Ulnar & Wrist & Digit 5 & $<2.1$ & $<3.0$ & $>15$ & $>52$ & 11 \\
\hline Radial & Forearm & Wrist & $<1.9$ & $<2.8$ & $>20$ & $>48$ & 10 \\
\hline Sural & Calf & Ankle & $<3.2$ & $<4.4$ & $>6$ & $>42$ & 14 \\
\hline \multicolumn{7}{|r|}{ Sensory Nerve Conduction Studies } \\
\hline
\end{tabular}

AG - Above ulnar groove, BG - Below ulnar groove, AFH - Above fibular head, BFH - Below fibular head, SG - Spiral groove, TA Tibialis anterior, EDB - Extensor digitorum brevis, EIP - Extensor indicis proprius, ADM - Abductor digiti minimi, APB - Abductor pollicis brevis, AH - Abductor hallucis, PF - Popliteal fossa. Sensory studies were performed antidromically, amplitudes were measured from baseline to negative peak of SNAP.

\begin{tabular}{|c|c|c|c|c|}
\hline \multirow{2}{*}{$\begin{array}{c}\text { Ulnar Motor } \\
\text { Nerve Variables }\end{array}$} & \multicolumn{2}{|c|}{ P.B. Patients (n= 30) } & \multicolumn{2}{c|}{ M.B. Patients } \\
\cline { 2 - 5 } & Range & Mean & Range & Mean \\
\hline CV m/s & $0-71.79$ & 55.58 & $0-52.17$ & 44.3 \\
\hline D.L. ms & $0-20.51$ & 10.472 & $0-3.5$ & 5.99 \\
\hline Amp mV & $0-23.57$ & 33.539 & $0-29.35$ & 10.472 \\
\hline \multicolumn{4}{|c|}{ Ulnar Motor Nerve Conduction Results } \\
\hline
\end{tabular}

$\mathrm{m} / \mathrm{s}=$ meters per seconds, $\mathrm{ms}=$ milliseconds, $\mathrm{mV}$ - millivolts

There is a significant reduction in NCV and amplitude and reduced latency in MB cases when compared to PB. In 3 cases of multibacillary leprosy, motor component of ulnar nerve could not be elicited with maximum stimulation.

\begin{tabular}{|c|c|c|c|c|}
\hline Sural Nerve & P.B. Patients (n = 22) & \multicolumn{2}{c|}{ M.B. Patients (n - 14) } \\
\cline { 2 - 5 } $\begin{array}{c}\text { Sensory } \\
\text { Variables }\end{array}$ & Range & Mean & Range & Mean \\
\hline CV m/s & $0-61.9$ & 42.54 & $0-52.46$ & 13.32 \\
\hline D.L. ms & $0-5.1$ & 2.32 & $0-3.25$ & 0.86 \\
\hline Amp mV & $0-42.31$ & 16.25 & $0-15.50$ & 3.51 \\
\hline \multicolumn{4}{|c|}{ Sural Nerve Conduction Results in Leprosy Patients } \\
\hline
\end{tabular}

There is a significant reduction in the nerve conduction velocity in all MB cases when compared to $\mathrm{PB}$ cases, in 10 cases of MB and 4 cases of $\mathrm{PB}$ the sural nerve could not be elicited even with maximum stimulation.

\begin{tabular}{|c|c|c|c|c|}
\hline \multirow{2}{*}{$\begin{array}{c}\text { Motor Nerve } \\
\text { Variables of } \\
\text { CPN }\end{array}$} & \multicolumn{2}{|c|}{$\begin{array}{c}\text { PB patients } \\
\text { (n= 12) }\end{array}$} & \multicolumn{2}{c|}{$\begin{array}{c}\text { MB patients } \\
\text { (n - 07) }\end{array}$} \\
\cline { 2 - 5 } & Range & Mean & Range & Mean \\
\hline CV m/s & $0-58.82$ & 40.99 & $0-52.4$ & 34.6 \\
\hline D.L. ms & $0-24.62$ & 8.47 & $0-16.4$ & 9.4 \\
\hline Amp mV & $0-24.62$ & 5.16 & $0-16.6$ & 4.2 \\
\hline \multicolumn{3}{|c|}{ Motor Nerve Conduction Results of } \\
Common Peroneal Nerve \\
\hline
\end{tabular}

There is a significant reduction of NCV and slight reduction in amplitude and prolongation of D.L. in MB cases when compared to PB cases, in 3 cases of MB the nerve could not be elicited even with maximum stimulation.

\begin{tabular}{|c|c|c|c|c|}
\hline \multirow{2}{*}{$\begin{array}{c}\text { PTN } \\
\text { Conduction } \\
\text { Variables }\end{array}$} & \multicolumn{2}{|c|}{$\begin{array}{c}\text { P.B. Patients } \\
\text { (n= 12) }\end{array}$} & \multicolumn{2}{c|}{$\begin{array}{c}\text { M.B. patients } \\
\text { (n - 08) }\end{array}$} \\
\cline { 2 - 5 } & Range & Mean & Range & Mean \\
\hline CV m/s & $0-58.02$ & 41.69 & $0-56.25$ & 36.34 \\
\hline D.L. ms & $0-19.25$ & 5.82 & $0-21.3$ & 6.46 \\
\hline Amp mV & $0.38-22.4$ & 11.23 & 0.38 .20 .2 & 9.46 \\
\hline \multicolumn{2}{|c|}{ Nerve Conduction Results of Posterior Tibial Nerve } \\
\hline
\end{tabular}

There is a slight reduction in NCV and amplitude and slight increase in DL in MB cases when compared to PB cases, in $1 \mathrm{MB}$ case the PTN could not be elicited even with maximum stimulation.

\begin{tabular}{|c|c|c|}
\hline Facial nerve & \multicolumn{2}{|c|}{ PB - 3 } \\
\cline { 2 - 3 } Conduction variables & Range & Mean \\
\hline DL & $2.62-9.68$ & 6.2 \\
\hline Amplitude & $2.23-2.98$ & 2.52 \\
\hline \multicolumn{2}{|c|}{ Facial Nerve Conduction Results } \\
\hline
\end{tabular}

There is a slight reduction in amplitude of facial nerve and increase in the DL.

\begin{tabular}{|c|c|c|c|c|}
\hline Nerves & $\begin{array}{c}\text { Clinically } \\
\text { Involved }\end{array}$ & $\begin{array}{c}\text { Clinically } \\
\text { Not } \\
\text { Involved }\end{array}$ & $\begin{array}{c}\text { Electrophy- } \\
\text { siologically } \\
\text { Involved }\end{array}$ & $\begin{array}{c}\text { Electrophy- } \\
\text { siologically } \\
\text { Not Involved }\end{array}$ \\
\hline Facial & & & 2 & \\
\hline Radial & 4 & & 4 & \\
\hline Ulnar & 36 & & 27 & 9 \\
\hline CPN & 17 & & 4 & \\
\hline PTN & 8 & & 1 & \\
\hline Sural & 3 & & 14 & \\
\hline \multicolumn{5}{|c|}{ Clinical \& Electrophysiological Correlation } \\
of Peripheral Nerves in Leprosy \\
\hline
\end{tabular}


There is a significant clinical and electrophysiological correlation seen only in ulnar and radial nerves. 17 CPN \& 8 PTN were clinically thickened and palpable but only few cases (4 CPN \& 1 PTN) were having significant and specific electrophysiological changes.

\section{DISCUSSION}

Early detection of neuropathy and therapy plays an important role in prevention of disabilities and deformities which is an integral part of leprosy control programs. Electrophysiological studies of peripheral nerves may help to detect neuropathy at an early stage. Though sural nerve not palpable clinically, nerve conduction studies showed marked electrophysiological changes correlated with the study by Van Brakel and Khwas et al. ${ }^{1}$ In our study, 14 cases of sural, 5 cases of ulnar though clinically unaffected, nerve conduction studies showed significant reduction in amplitude. Similar observations were made by Ramakrishnan and AG Srinivasan. ${ }^{2}$ There is delay in nerve conduction velocity in all MB cases compared to PB cases. This is comparable with study by Sheela V. Donde. ${ }^{3}$ In our study, median sensory component was more commonly affected than motor component compared with study by Soyal and Samanth et al. ${ }^{4}$ In our study, 5 claw hands and 1 lagophthalmos detected by electrophysiological studies. In our study, lower limbs were severely affected than upper limbs, sensory more involved than motor comparable to Soyal et al. ${ }^{4}$ In our study of 50 cases, peripheral neuropathy was variable compared to Goel et al.5 In our study neurological and electrophysiological abnormalities were related to duration of disease in $10 \mathrm{MB}$ cases compared to Brown T.R et al. ${ }^{6}$ In our study, $10 \mathrm{MB}$ cases showed diffuse involvement in most of the peripheral nerves compared to PB correlated with study by Tzourio et al.7 In our study, mononeuritis of ulnar nerve was observed in 11 cases and it was the commonest nerve affected compared with study by $\mathrm{S}$ Talwar et al. ${ }^{8}$ In this study, pure neuritic cases constitute about $18 \%$ compared with study by Kumar B et al. ${ }^{9}$ In our study, motor component of ulnar nerve was more affected than motor component of median nerve compared to study by Antia et al.10 There is a markedly significant increase in stimulating strength in all patients even in cases with normal conduction velocities. It indicates strength of the stimulus used is very sensitive and an important test for early detection of nerve involvement comparable to study by DD Palende et al. ${ }^{11}$ Electrophysiological studies are only supplementary to clinical and standard tests to detect nerve function impairment. These tests are simple and noninvasive.

\section{CONCLUSION}

All patients of leprosy should have nerve function assessment in every visit during first year of treatment. Regular nerve function assessment is essential to detect silent neuropathy to prevent permanent disabilities and deformities. Hence, nerve conduction studies along with these tests may definitely help to assess the damaged nerves in leprosy.

\section{REFERENCES}

[1] Van Brakel WH, Khawas IB. Silent neuropathy in leprosy; an epidemiological description. Lepr Rev 1994;65(4):350-60.

[2] Ramakrishnan AG, Srinivasan TM. Electrophysiological correlates of hanseniasis. Int J Lepr Other Mycobact Dis 1995;63(3):395-408.

[3] Donde SV, Shah A, Antia NH. Nerve conduction in leprosy: in vivo and in vitro study. Lepr India 1983;55(1):12-21.

[4] Soysal A, Atay T, Ozu T, et al. Electrophysiological evaluation of peripheral and autonomic involvement in leprosy. Can J Neurol Sci 2004;(3):357-62.

[5] Goel UC, Gupta OP, Bajaj S, et al. Clinical profile and electrodiagnostic study of peripheral neuropathy. J Assoc Physicians India 1989;37(9):578-82.

[6] Brown TR, Kovinda A, Wathanadilokkol V, et al. Leprosy neuropathy: correlation of clinical and electrophysiological tests. Indian J Lepr 1996;68(1):114.

[7] Tzourio C, Henry P, Boucher P, et al. Lepromatous leprosy; clinical and electrophysiological arguments in favour of areonal multi neuritis. Acta Leprol 1989;7(1):51-6.

[8] Talwar S, Jha PK, Tiwari VD. Neuritic leprosy: epidemiological and therapeutic responsiveness. Lepr Rev 1992;63(3):263-8.

[9] Kumar B, Kaur I, Dogra S, et al. Pure neuritic leprosy in India: an appraisal. Int J Lepr Other Mycobact Dis 2004;72(3):284-90.

[10] Antia NH, Mehta L, Shetty V, et al. Clinical electro physiological, quantitative histologic and ultrastructural studies of the index branch of the radial cutaneous nerve in leprosy 1 . Preliminary report. Int J Lepr 1975;43(2):106.

[11] Palande DD, Bowden RE. Early detection of damage to nerves in leprosy. Lepr Rev 1992;63(1):60-72. 